\title{
Discovery of Geographically Robust Hybrid Poplar Clones
}

\author{
Neil D. Nelson ${ }^{1 *}$, William E. Berguson', Bernard G. McMahon', Richard Meilan², Lawrence B. \\ Smart ${ }^{3}$, Fred E. Gouker ${ }^{4}$, Paul Bloese ${ }^{5}$, Raymond Miller ${ }^{5}$, Timothy A. Volk ${ }^{6}$, Meijun Cai ${ }^{1}$, and Daniel \\ Buchman ${ }^{1}$
}

\begin{abstract}
${ }^{1}$ University of Minnesota Duluth NRRI, 5013 Miller Trunk Highway, Duluth, MN 55811-1442
${ }^{2}$ Department of Forestry and Natural Resources and Purdue Center for Plant Biology, 715 W. State Street, West Lafayette, IN 47907-2061, ORCID: 0000-0002-8680-1110 (R.M.)

${ }^{3}$ School of Integrative Plant Science, Horticulture Section, Cornell University, 630 West North Street, Geneva, NY 14456, ORCID 0000-0002-7812-7736

${ }^{4}$ Floral and Nursery Plants Research Unit, U.S. National Arboretum, U.S. Department of Agriculture, Agricultural Research Service, 10300 Baltimore Avenue, Beltsville, MD 20705, ORCID toget0001-8781-8689

${ }^{5}$ Department of Forestry, Michigan State University, Natural Resources Building, 480 Wilson Road, Room 126, East Lansing, MI 48824-6402

${ }^{6}$ SUNY College of Environmental Science and Forestry, 346 Illick Hall, 1 Forestry Drive, Syracuse, NY 13210
\end{abstract}

*Corresponding author: Neil D. Nelson, Email: nnelson2@d.umn.edu

\begin{abstract}
Hybrid poplar clonal growth in the states (regions) of Minnesota (MN), Indiana (IN), Michigan (MI), and New York (NY) USA was analyzed to discover 10 geographically robust (georobust) clones, all $P$. deltoides $\times$ P. nigra $(\mathrm{D} \times \mathrm{N})$ hybrids previously tested and screened in $\mathrm{MN}$, that were broadly adapted across latitudinal and longitudinal ranges of 9 and 20 degrees, respectively. The clonal effect for growth explained 25 to $36 \%$ of the total variance, $2.5-4.1$ times the clone $x$ site interaction. Clone explained 24 to $46 \%$ of total variation in canker occurrence on two sites. Genetic gain in growth was calculated relative to commercial check clones. Genetic gain in growth of georobust clones exceeded that of random clones by 24 to $44 \%$. Geo-robust clones and the best clones on each site were not significantly different on the MN sites, but best clones outperformed geo-robust clones on the other sites by 10 to $39 \%$ genetic gain. Geo-robust clones grew faster than commercial check clones on all but the MI site. The reduction in genetic gain for growth due to using broadly adapted clones relative to the best clones has to be compared to the additional costs and benefits of multiple breeding zones.
\end{abstract}

Key words: breeding zones, clonal adaptability, genotype x environment interaction, hybrid poplars, Populus

\section{Introduction}

Hybrid poplars are one of the primary dedicated energy crops needed to meet national targets for bioenergy in the USA (US DOE, 2016). However, investments in hybrid poplar programs are not expected to support narrow breeding zones or the tailoring of individual clones to specific sites (Nelson et al., 2018), ie., specialist genotypes (Zalesny et al., 2009). Accordingly, the emphasis of our hybrid poplar breeding program at the Natural Resources Research Institute (NRRI) has evolved so that we are now identifying families and clones that are fast-growing and broadly adapted to a range of soils, climates and geographic regions, ie., generalist genotypes (Zalesny et al., 2009). Fortunately, two studies preceding the one reported here provide evidence that this approach may be successful. Nelson et al. $(2018,2019)$ documented a strong clonal effect for growth rate that accounted for 3-4 times more of the variation than the clone $x$ site (genotype $x$ environment, $G \times E$ ) interaction on a range of sites in Minnesota (MN, USA) and Indiana (IN, USA), and no change of rank between six sites in $\mathrm{MN}$ nor between two sites without irrigation or fertilization in IN.

The focus of the NRRI program is the Populus deltoides $x$ Populus nigra ( $\mathrm{D} \times \mathrm{N}, \mathrm{DN}$ ) cross. Both P. deltoides and P. nigra are riparian species and are within the Aigeiros section of Populus. Whereas $P$. deltoides is a North American species, $P$. nigra is a pan-European species that extends into Asia Minor. The $P$. 
deltoides female parent of MN origin provides resistance to Septoria (Sphaerulina musiva) canker and adaptability to harsh northern temperate conditions. The $P$. nigra male parent imparts varying amounts of rust resistance. Moreover, the $P$. nigra component in $\mathrm{D} \times \mathrm{N}$ hybrids contributes rootability among individual $\mathrm{D} \times \mathrm{N}$ pedigreed selections so that unrooted cuttings can be used for plantation establishment, which is critical for commercial deployment. $\mathrm{D} \times \mathrm{N}$ clones developed in MN did surprisingly well in northwestern and southwestern IN field tests 5-9 degrees latitude south and 8-9 degrees longitude east of where the clones were developed in northern MN (Nelson et al., 2019), with significant representation in the top $10^{\text {th }}$ percentile for growth. An even more surprising result of that study was that the clonal rank for growth rate did not change for 19 clones common to six test sites in northern MN and the two IN sites. Our hypothesis is that $\mathrm{D} \times \mathrm{N}$ hybrids with a female parent of MN origin can provide very broad adaptability to sites of wide latitudinal and longitudinal range. Cooperative studies in Michigan (MI, USA) and New York (NY, USA) being reported here with clones common to the previous $\mathrm{MN}$ and IN tests provide an opportunity to further test and possibly extend the adaptability inferences associated with our hypothesis. This meta-analytic study takes advantage of the greater power of clonal populations for detecting $\mathrm{G} \times \mathrm{E}$ interactions, in contrast to using families and seed sources (Bentzer et al., 1988; Yu and Pulkkinen, 2003) and the statistical robustness of non-parametric rank correlations.

\section{Materials and Methods}

\section{Study design}

The MN, MI and NY field tests were conducted using randomized complete blocks, while the IN field tests were designed as a completely random design within four cultural treatment blocks. The details of the $\mathrm{MN}$ and IN experimental designs are described in Nelson et al. $(2018,2019)$. The MI (Escanaba) and NY (Cornell, Tully) designs each entailed six blocks, and each clone was represented by a single-tree plot located randomly within each block.

\section{Plant material}

Clone selection for tests-

The clones in the MN and IN tests are described in Nelson et al. $(2018,2019)$. The clones in the MI and NY tests are listed in Table 1. Seventy-three percent of the clones in the MI and NY tests were $\mathrm{D} \times \mathrm{N}$ hybrids, $96 \%$ of which had $P$. deltoides parents of $\mathrm{MN}$ origin and were bred, tested and screened in MN by the NRRI Hybrid Poplar Program. The NRRI breeding and testing process is diagrammed in Nelson et al. (2018). The commercial standard clone, NM6, was embedded in all trials as a check. Some trials also included two other commercial standard check clones, DN5 (IN, Cornell and Tully) and DN2 (MN, MI).

Table 1

Characteristics of clones established on the Escanaba, Cornell and Tully sites.

\begin{tabular}{|c|c|c|c|c|c|}
\hline Clone ID & Cross & $\begin{array}{l}\text { Female Parent } \\
\text { Origin }\end{array}$ & Male Parent Origin & $\begin{array}{l}\text { Common } \\
\text { Clones } \\
\text { to All } \\
\text { Sites (inc } \\
\text { IN) }\end{array}$ & $\begin{array}{c}\text { Common } \\
\text { Clones } \\
\text { to All } \\
\text { Sites } \\
\text { Except } \\
\text { IN }\end{array}$ \\
\hline 502.37 & DxM & unknown & unknown & Yes & Yes \\
\hline 6300 & $\mathrm{DxN}$ & D109 & N964-1 & No & No \\
\hline 21700 & $\mathrm{DxN}$ & D109 & $\mathrm{N} 949-2$ & No & No \\
\hline 22700 & $\mathrm{DxN}$ & D109 & N949-2 & No & No \\
\hline 23300 & DxN & D109 & N949-2 & No & No \\
\hline 24400 & DxM & D109 & M1052-3 & No & No \\
\hline 31500 & DXN & D109 & N964-1 & No & No \\
\hline 41700 & $\mathrm{DxN}$ & $288-5$ & N944-4 & No & No \\
\hline 20113214 & DxN & D109 & N949-2 & No & No \\
\hline 22021008 & DxN & D125 & N40 & No & Yes \\
\hline 22021009 & DxN & D125 & N40 & No & No \\
\hline 22021018 & DxN & D125 & $\mathrm{N} 40$ & No & No \\
\hline 22021021 & DxN & D125 & N40 & No & No \\
\hline 22021048 & DxN & D125 & $\mathrm{N} 40$ & No & Yes \\
\hline 22057002 & $\mathrm{DxN}$ & D121 & N40 & No & No \\
\hline 22057006 & DxN & D121 & N40 & No & No \\
\hline 22057030 & DxN & D121 & $\mathrm{N} 40$ & No & No \\
\hline 22057032 & $\mathrm{DxN}$ & D121 & N40 & No & No \\
\hline 22066086 & $\mathrm{Dx}(\mathrm{TD})$ & $180-1$ & $50-197$ & No & No \\
\hline 22066094 & $\mathrm{Dx}(\mathrm{TD})$ & $180-1$ & $50-197$ & No & No \\
\hline 22069011 & DxN & $180-1$ & N88 & No & No \\
\hline 22090032 & $\operatorname{TDx}(\mathrm{D})$ & $52-225$ & D113 & No & No \\
\hline 22091021 & $\operatorname{TDx}(\mathrm{D})$ & $52-225$ & D105 & No & No \\
\hline 22091022 & $\operatorname{TDx}(\mathrm{D})$ & $52-225$ & D105 & No & Yes \\
\hline 22091039 & $\operatorname{TDx}(\mathrm{D})$ & $52-225$ & D105 & No & No \\
\hline 22091051 & $\operatorname{TDx}(\mathrm{D})$ & 52-225 & D105 & No & No \\
\hline 99001111 & $\mathrm{DXN}$ & D121 & N947-5 & No & No \\
\hline 99007071 & DxN & D121 & N949-2 & Yes & Yes \\
\hline 99007108 & DxN & D121 & N949-2 & No & Yes \\
\hline 99007115 & DxN & D121 & N949-2 & Yes & Yes \\
\hline 99007116 & DxN & D121 & N949-2 & Yes & Yes \\
\hline 99008002 & DxN & D121 & N944-4 & No & Yes \\
\hline 99008070 & DxN & D121 & N944-4 & No & Yes \\
\hline 99008080 & DxN & D121 & N944-4 & No & No \\
\hline 99008081 & $\mathrm{DxN}$ & D121 & N944-4 & No & No \\
\hline 99008098 & DxN & D121 & N944-4 & No & No \\
\hline 99037044 & DxN & D200 & N964-6 & No & No \\
\hline 99037017 & DxN & D200 & N964-6 & No & No \\
\hline 99037039 & DxN & D200 & N964-6 & No & No \\
\hline 99037046 & DxN & D200 & N964-6 & No & No \\
\hline 99037049 & $\mathrm{DxN}$ & D200 & N964-6 & Yes & Yes \\
\hline 99037051 & DxN & D200 & N964-6 & No & No \\
\hline 99037053 & DxN & D200 & N964-6 & No & No \\
\hline 99038002 & DxN & D200 & N944-4 & No & No \\
\hline 99038003 & $\mathrm{DxN}$ & D200 & N944-4 & No & Yes \\
\hline 99038005 & DxN & D200 & N944-4 & No & Yes \\
\hline 99038007 & DxN & D200 & N944-4 & No & No \\
\hline 99038013 & DxN & D200 & N944-4 & Yes & Yes \\
\hline 99038022 & DxN & D200 & N944-4 & No & Yes \\
\hline 99038026 & DxN & D200 & N944-4 & No & No \\
\hline 99038036 & DxN & D200 & N944-4 & No & No \\
\hline 99059016 & DxN & D123 & N949-2 & Yes & Yes \\
\hline 99059043 & DxN & D123 & N949-2 & No & Yes \\
\hline 99098008 & DxN & 14 Crookston & N964-6 & No & No \\
\hline 99105008 & DxN & 14 Crookston & N944-4 & Yes & Yes \\
\hline 99105088 & $\mathrm{DxN}$ & 14 Crookston & N944-4 & No & Yes \\
\hline $152 \times 11861$ & DxM & P. deltoides '152' & P. maximowiczii '11861' & No & Yes \\
\hline 230013057 & $\operatorname{TDx}(\mathrm{D})$ & $52-225$ & D133 & No & No \\
\hline 2305932018 & DxN & D110 & SO N147 & No & No \\
\hline $9732-11$ & DxN & D125 & N946-2 & Yes & Yes \\
\hline 9732-19 & $\mathrm{DxN}$ & D125 & N946-2 & No & Yes \\
\hline $9732-24$ & DxN & D125 & N946-2 & Yes & Yes \\
\hline 9732-31 & DxN & D125 & N946-2 & No & Yes \\
\hline $9732-32$ & DxN & D125 & N946-2 & No & No \\
\hline D105 & $\begin{array}{l}\text { OP } P \text {. } \\
\text { deltoides }\end{array}$ & $\begin{array}{l}\text { UM OP family } \\
904 \text { mother }\end{array}$ & wind pollinated & No & No \\
\hline D109 & $\begin{array}{l}\text { OP } P \text {. } \\
\text { deltoides }\end{array}$ & $\begin{array}{l}\text { UM OP family } \\
400 \text { mother }\end{array}$ & wind pollinated & No & No \\
\hline D110 & $\begin{array}{l}\text { OP } P \text {. } \\
\text { deltoides }\end{array}$ & $\begin{array}{l}\text { UM OP family } \\
908 \text { mother }\end{array}$ & wind pollinated & No & No \\
\hline D111 & $\begin{array}{l}\text { OP } P \text {. } \\
\text { deltoides }\end{array}$ & $\begin{array}{l}\text { UM OP family } \\
908 \text { mother }\end{array}$ & wind pollinated & No & No \\
\hline D113 & $\begin{array}{l}\text { OP } P \text {. } \\
\text { deltoides }\end{array}$ & $\begin{array}{l}\text { UM OP family } \\
400 \text { mother }\end{array}$ & wind pollinated & No & No \\
\hline D124 & $\begin{array}{l}\text { OP } P \text {. } \\
\text { deltoides }\end{array}$ & $\begin{array}{l}\text { UM OP family } \\
400 \text { mother }\end{array}$ & wind pollinated & No & No \\
\hline D125 & $\begin{array}{l}\text { OP } P \text {. } \\
\text { deltoides }\end{array}$ & $\begin{array}{l}\text { UM OP family } \\
400 \text { mother }\end{array}$ & wind pollinated & No & No \\
\hline DN164 & DxN & unknown & unknown & No & No \\
\hline $\begin{array}{l}\text { DN2 } \\
\text { (commercial } \\
\text { check clone) }\end{array}$ & $\mathrm{DxN}$ & unknown & unknown & No & No \\
\hline $\begin{array}{l}\text { DN5 } \\
\text { (commercial }\end{array}$ & DxN & unknown & unknown & No & No \\
\hline $\begin{array}{l}\text { check clone) } \\
\text { NC14106 }\end{array}$ & DxM & unknown & unknown & No & No \\
\hline $\begin{array}{l}\text { NM6 } \\
\text { (commercial } \\
\text { check clone) }\end{array}$ & $\mathrm{N} \times \mathrm{M}$ & unknown & unknown & Yes & Yes \\
\hline
\end{tabular}




\section{Plant propagation}

Propagation methods for the MN and IN tests are described by Nelson et al. $(2018,2019)$. Rooted cuttings were used in the MI test and propagation methods were the same as for the MN test, as described by Nelson et al. (2018). Unrooted cuttings (20.3 cm in length) were utilized in the NY tests, with cuttings harvested in winter from dormant stools in a cutting orchard at the University of Minnesota North Central Research and Outreach Center (NCROC) nursery near Grand Rapids, MN, and stored at sub-freezing temperatures.

\section{Study locations}

The geographic coordinates and information on soils and climate for the MI and NY test sites are in Table 2. The MN and IN sites are described in Nelson et al. $(2018,2019)$. The latitudinal and longitudinal ranges for the MN, IN, MI and NY sites were 9 degrees and 20 degrees, respectively. All tests were established on agricultural soils.

\section{Table 2}

Location, soil and climate information for Escanaba, Cornell and Tully test sites.

\begin{tabular}{|llll|}
\hline Site & Escanaba & Cornell & Tully \\
\hline County & Delta & Ontario & Onondaga \\
Nearest town & Escanaba, MI & Geneva, NY & Tully, NY \\
Latitude & 45.7712 & 42.8810 & 42.7959 \\
Longitude & -87.1992 & -77.0119 & -76.1177 \\
Slope\% & $1-6$ & $0-3$ & $0-3$ \\
Soil texture & fine sandy & & \\
Soil pH & loam & & \\
Soil particulate organic matter $(\%)$ & 6.5 & 6.8 & 6.5 \\
Soil bulk density $(\mathrm{g} / \mathrm{cm} 3)$ & 1.58 & 4.4 & 5 \\
& 1.43 & 1.17 & 1.25 \\
Average high/low temperature $(\circ \mathrm{C})$ & & & \\
Growing degree days during study $($ base $10 \circ \mathrm{C} / 30 \circ \mathrm{C})$ & 1,967 & 2,653 & 2,256 \\
Long term average precipitation $(\mathrm{mm})$ & 724 & 850 & 1164 \\
\hline
\end{tabular}

Soil data from https://websoilsurvey.sc.egov.usda.gov/App/HomePage.htm

Climate data from https://www.usclimatedata.com/ U.S. Climate Data, three-decade (1981-2010) averages (National Centers for Environmental Information, NOAA).

\section{Plantation establishment and maintenance}

Establishment and weed control methods for the MN and IN sites are described in Nelson et al. $(2018,2019)$.

\section{MI (Escanaba) site:}

The clonal trial at Michigan State University Forest Biomass Innovation Center (FBIC) contained 56 clones and was established at $1.5 \times 2.4 \mathrm{~m}$ spacing with containerized, pre-rooted 'mini' cuttings in July 2008 , using dibble bars. To prepare the site, the remaining stubble from a winter wheat crop was sprayed with glyphosate and rototilled 10 days later. Vegetative buds on the containerized plants had already elongated at the time of planting. Accord ${ }^{\circledR}$ (glyphosate) herbicide was applied at 0.96 liters of active ingredient (a.i.) per hectare with a shielded sprayer, seven days post planting. Midway through the first two growing seasons, mechanical weed maintenance was done with a tiller and spring harrow. After the first two growing seasons and when plants were dormant (December 2009), a pre-emergent herbicide tank mix of Pendulum Aqua Cap ${ }^{\oplus}$ (pendimethalin) (2.26 a.i./hectare) and Scepter 70DG ${ }^{\circledR}$ (imazaquin) (0.29 liters a.i./hectare) was applied. Spot treatments of insecticide (Bacillus thuringiensis (BT), mixed as $9.9 \mathrm{ml}$ dry powder per 3.79 liters) were applied as needed to control mourning cloak butterfly (Nymphalis antiopa) larvae.

\section{NY (Cornell) site:}

The clonal trial at Cornell University was located at Cornell AgriTech in Geneva, NY, contained 49 clones (identical to 49 of 50 clones in the Tully trial) and was established at $1.8 \times 1.8 \mathrm{~m}$ spacing in June 2012. The 2011 wheat crop on this site while it was fallowed was sprayed with glyphosate in May 2012 to kill existing vegetation. The site was moldboard plowed and disked several times to prepare it for planting.

Dormant hardwood cuttings $(20.3 \mathrm{~cm}$ in length) were hand-planted with a dibble bar. A pre-emergent herbicide was applied on the following day (June $22^{\text {nd }}$ ). The pre-emergent chemical product used was SureGuard ${ }^{\circledR}$ and was applied at the label rate of 420.32 grams per hectare (or 210/16 grams active ingredient per hectare). Due to the dry weather conditions, a drip-irrigation system was completed on the day of planting and was used to provide irrigation during the periods of dry weather in the first growing season as needed. A minor number of replants were needed and were made after three assessments in July 2012.

NY (Tully) site:

The clonal trial at the SUNY ESF Tully site contained 50 clones (49 identical to the 49 clones in the Cornell trial) and was established at $1.8 \times 1.8 \mathrm{~m}$ spacing in late May 2012 with unrooted cuttings shipped at sub-freezing temperatures in ice chests from NRRI. The trial location had been fallow for two years prior to planting and was most recently planted with a winter rye cover crop in the fall of 2010. In late April 2012, the field was sprayed with glyphosate $(2.2 \mathrm{~kg}$ ai ha-1) and then rototilled ten days later.

Each dormant hardwood cutting $(20.3 \mathrm{~cm}$ in length) was driven into the ground with a rubber mallet at a predetermined position. A single bud was left aboveground for each cutting.

The field was sprayed with a pre-emergent herbicide cap (Goal ${ }^{\oplus} 1.1 \mathrm{~kg}$ ai/ha) within one week of planting. A small amount of spot spraying was done with glyphosate during the first growing season to kill weeds that sprouted when the preemergence cap broke down or was disturbed. Initial 
assessment of survival was conducted in June and July 2012. About 4-5 replacement cuttings per block were planted on June $11^{\text {th }}$. Initial survival measured in July 2012 was $98 \%$.

\section{Measurements}

Stand age at measurement was: MN and Cornell -4 years, Escanaba and Tully - 5 years, IN -3 years. Growth parameters used in ranking and genetic gain calculations were: $\mathrm{MN}$ - basal area $\left(\mathrm{cm}^{2}\right)$, IN - tree bole volume $\left(\mathrm{cm}^{3}\right)$, Escanaba and Cornell $\mathrm{DBH}^{2}$, Tully - tree height. Diameters were not measured at the Tully site; height was the only growth parameter measured there.

Canker scoring was not done at the IN or Cornell sites. Canker score had different bases for MN, Escanaba and Tully. The canker scoring system for MN, as described in Nelson et al. (2018), was as follows: 0 = cankers absent, $1=$ cankers present but rare, 2 = cankers present with multiple areas of sunken, necrotic tissue on main bole or branches. For the Escanaba trial, the following scoring was used: 1 = no cankers (absent), 2 = slight cankering, 3 = moderate cankering, $4=$ severe cankering. At the Tully site, the following scoring was used: $1=$ no cankers (absent), 2 = cankers present but rare, 3 = obvious moderate to heavy incidence of Septoria (Sphaerulina musiva) canker(s) with typical sunken canker.

\section{Statistical analyses}

Growth parameters chosen for the ANOVA tests were: MN ->basal area (Nelson et al., 2018); IN ->total tree bole volume calculated from diameter and height as described in Nelson et al., 2019; Escanaba $->\mathrm{DBH}, \mathrm{DBH}^{2}$ and tree height; Cornell $->\mathrm{DBH}^{2}$ and tree height; Tully $->$ tree height. For plantations of a given age and spacing, the allometric relationships between tree height, diameter, diameter squared, basal area and bole volume should theoretically produce approximately the same statistical test results for any of these four parameters. This assumption was confirmed by the ANOVA for $\mathrm{DBH}, \mathrm{DBH}^{2}$ and height at Escanaba and Cornell (see Table 5). Diameter squared $\left(\mathrm{DBH}^{2}\right)$ was used in clone ranking and rank similarity tests for Escanaba and Cornell to be as similar as possible to the MN and IN growth parameters, which utilized basal area and total tree bole volume, respectively. Tree height was also used for ranking clones on the Escanaba and Cornell sites to compare with the ranking using $\mathrm{DBH}^{2}$. Canker scores were not taken for the IN and Cornell sites, and different canker scoring systems were used for MN, Escanaba and Tully, so canker scores cannot be directly compared for these sites. ANOVA tests were performed in $R$ 3.5.1 by using function aov from the $R$ basic package to achieve the sum of squares for clone types and errors. This test used one of the growth parameters as $y$ variable and clone as $x$ variable. To compute the variance components of growth parameters, a random effects model was fitted by the Imer function from the package of Ime4, and clone was the only predictor and treated as a random variable. The site and site $\mathrm{x}$ clone effects could not be calculated for the Escanaba, Cornell and
Tully sites due to differences in clone populations, measurement variables and age of measurement.

The canker scores for Escanaba and Tully are ordinal values and thus cannot be analyzed with ordinary ANOVA methods. The clone effect on canker score was analyzed with the ordinal logistic model fit method. Model fitting was performed in JMP Pro 14. Pseudo $R^{2}$ was calculated by McFadden's $R$ squared measure.

The growth parameters and canker score were averaged for each clone within each site. The mean values of growth parameters were ranked from the largest $=1$ to the smallest. Growth parameters and canker score were averaged for all clones within each site to calculate average site values. Spearman's Test of Rank Correlation was used to compare similarity of ranks between sites. Two Spearman's Tests were done to compare clone ranks between sites: 1) 12 clones common to all sites (MN, IN, Escanaba, Cornell and Tully); and 2) 27 clones common to all sites excluding IN. Spearman's Test was also used to compare clone rankings based on $\mathrm{DBH}^{2}$ and tree height within the Escanaba and Cornell sites.

Genetic gains for growth rate were calculated as the increase in growth for clones over the mean growth of the commercial check clones, divided by mean growth of the check clones. The genetic gains for Tully could not be directly compared or combined with genetic gain values for the MN, IN, Escanaba and Cornell sites because only height was measured at Tully, and height has a much lower coefficient of variation than does $\mathrm{DBH}^{2}$ (Table 3).

Table 3

Mean site growth parameters and canker scores for all clones on the Escanaba, Cornell and Tully sites.

\begin{tabular}{|c|c|c|c|c|c|c|c|}
\hline Site & $\begin{array}{l}\text { Age } \\
\text { measured } \\
\text { (years) }\end{array}$ & $\begin{array}{l}\text { Spacing } \\
\text { (m) }\end{array}$ & Parameter & Unit & $\begin{array}{l}\text { Count } \\
\text { (number of } \\
\text { clones) }\end{array}$ & Mean & $\begin{array}{l}\text { Standard } \\
\text { Deviation } \\
\text { (CV) }\end{array}$ \\
\hline \multirow[t]{4}{*}{ Escanaba } & \multirow[t]{4}{*}{5} & \multirow[t]{4}{*}{$1.5 \times 2.4$} & DBH & $\mathrm{cm}$ & 56 & 5.59 & $\begin{array}{l}1.66 \\
(29.70 \%)\end{array}$ \\
\hline & & & $\mathrm{DBH}^{2}$ & $\mathrm{~cm}^{2}$ & 56 & 33.87 & $\begin{array}{l}20.22 \\
(59.70 \%)\end{array}$ \\
\hline & & & Height & $\mathrm{m}$ & 56 & 7.55 & $\begin{array}{l}0.98 \\
(12.98 \%)\end{array}$ \\
\hline & & & Canker score & & 56 & 1.93 & \\
\hline \multirow[t]{3}{*}{ Cornell } & \multirow[t]{3}{*}{4} & \multirow[t]{3}{*}{$1.8 \times 1.8$} & DBH & $\mathrm{cm}$ & 49 & 8.65 & $\begin{array}{l}1.42 \\
(16.42 \%)\end{array}$ \\
\hline & & & $\mathrm{DBH}^{2}$ & $\mathrm{~cm}^{2}$ & 49 & 78.99 & $\begin{array}{l}24.01 \\
(30.40 \%)\end{array}$ \\
\hline & & & Height & $\mathrm{m}$ & 49 & 7.87 & $\begin{array}{l}0.72 \\
(9.15 \%)\end{array}$ \\
\hline \multirow[t]{2}{*}{ Tully } & \multirow[t]{2}{*}{5} & \multirow[t]{2}{*}{$1.8 \times 1.8$} & Height & $\mathrm{m}$ & 50 & 8.55 & $\begin{array}{l}1.03 \\
(12.05 \%)\end{array}$ \\
\hline & & & Canker score & $\mathrm{m}$ & 50 & 1.49 & \\
\hline
\end{tabular}

$\mathrm{CV}=$ is coefficient of variation

No canker scoring for Cornell. Canker scores have different bases for Escanaba and Tully (see Measurements section for canker scoring systems), and so means cannot be directly compared. Canker scores are ordinal variables; standard deviation cannot be calculated. 
Geographic regions in this study are defined as MN, IN, MI (Escanaba) and NY (Cornell, Tully). Inter-regional clones are identified as those within the upper $10^{\text {th }}$ and/or $25^{\text {th }}$ percentile in two or more sites in different regions. Geographically robust (geo-robust) clones are considered all inter-regional clones without cankering. Clonal groups for each site included georobust clones, best clones, and other (random) clones.

Growth and genetic gains were compared for the three clonal groups within each site. Comparisons used geo-robust clones present on a site and an equal number of top-ranked clones (best clones) and equal number of other (random) clones that are not geo-robust or best clones for the site. Inclusion of the other (random) clone group was to eliminate the possibility that estimated genetic gain for geo-robust clones was not due to chance, as the populations are generally improved. As variances for growth and genetic gain were unequal for clonal groups within each site (determined by box plots), we used the non-parametric Steel-Dwass method (JMP Pro 14) to detect differences between the clonal group means within each site.

\section{Results}

\section{Means and analysis of variance}

Survival at age of measurements averaged $87 \%$ for the six MN sites (range $78 \%-95 \%$ ) and $97 \%$ for the two IN sites, and was $99 \%$ for the Escanaba MN site, $97 \%$ for the Cornell NY site and $95 \%$ for the Tully NY site. Site means for growth rate parameters for the six MN field tests and the two IN field tests are in Nelson et al. $(2018,2019)$. The site means for growth parameters and canker scores at Escanaba, Cornell and Tully are in Table 3. Growth at Escanaba was substantially slower than the mean performance in MN and IN and at Cornell and Tully. Canker scoring was done differently at the MN, Escanaba and Tully sites. As a consequence, canker scores cannot be directly compared between sites. However, the mean canker scores in $\mathrm{Nel}-$ son et al. (2018) and in Table 3 do indicate that cankers were not frequent in the MN, Ml and NY sites on which canker incidence was monitored, although specific clones were heavily cankered on certain sites (Table 4). Table 4 shows growth parameter values and canker scores for each clone at Escanaba, Cornell and Tully. Growth rates and canker scoring for clones on the MN sites are in Nelson et al. (2018), and growth rates for IN are in Nelson et al. (2019). $\underline{\text { Table } 4}$

Mean clone values for growth parameters used for ranking growth and canker scores for the Escanaba, Cornell and Tully sites.

\begin{tabular}{|c|c|c|c|c|c|c|c|c|}
\hline \multirow[b]{2}{*}{ Clone } & \multicolumn{3}{|c|}{ Escanaba } & \multicolumn{2}{|l|}{ Cornell } & \multicolumn{3}{|l|}{ Tully } \\
\hline & $\begin{array}{l}\text { Mean } \\
\mathrm{DBH}^{2} \\
\left(\mathrm{~cm}^{2}\right)\end{array}$ & Rank & $\begin{array}{l}\text { Mean } \\
\text { Canker } \\
\text { Score }\end{array}$ & $\begin{array}{l}\text { Mean } \\
\mathrm{DBH}{ }^{2} \\
\left(\mathrm{~cm}^{2}\right)\end{array}$ & Rank & $\begin{array}{l}\text { Mean } \\
\text { Height } \\
\text { (m) }\end{array}$ & Rank & $\begin{array}{l}\text { Mean Canker } \\
\text { Score }\end{array}$ \\
\hline 502.37 & 61.51 & 8 & 3.00 & 102.30 & 10 & 9.60 & 8 & 2.17 \\
\hline 6300 & 18.11 & 44 & 1.17 & & & & & \\
\hline 21700 & 15.62 & 50 & 1.33 & & & & & \\
\hline 22700 & 22.91 & 32 & 1.40 & & & & & \\
\hline 23300 & 28.26 & 26 & 1.00 & 72.66 & 29 & 8.76 & 31 & 1.17 \\
\hline 24400 & 20.29 & 39 & 1.33 & & & & & \\
\hline 31500 & 31.41 & 24 & 1.20 & & & & & \\
\hline 41700 & 65.91 & 6 & 1.00 & 82.79 & 25 & 9.24 & 12 & 1.00 \\
\hline 20113214 & & & & 93.34 & 16 & 9.15 & 16 & 2.00 \\
\hline 22021008 & 20.68 & 36 & 3.17 & 90.64 & 21 & 9.64 & 7 & 1.67 \\
\hline 22021009 & 30.68 & 25 & 3.40 & & & & & \\
\hline 22021018 & 52.63 & 12 & 3.80 & & & & & \\
\hline 22021021 & & & & 54.43 & 43 & 8.16 & 33 & 1.33 \\
\hline 22021048 & 23.93 & 30 & 3.40 & 68.39 & 32 & 9.21 & 13 & 1.20 \\
\hline
\end{tabular}

$\begin{array}{llll}22021051 & 47.04 & 15 & 3.40 \\ 22057002 & 27.90 & 27 & 4.00\end{array}$

$\begin{array}{llll}22057002 & 27.90 & 27 & 4.00\end{array}$

$\begin{array}{llll}22057006 & 21.94 & 33 & 4.00\end{array}$

$\begin{array}{llll}22057030 & 32.07 & 23 & 2.17 \\ 22057032 & 77.00 & 3 & 3.33\end{array}$

$\begin{array}{llll}22057032 & 77.00 & 3 & 3.33 \\ 2206006 & 21.38 & 34 & 3.50\end{array}$

$\begin{array}{llll}22066086 & 21.38 & 34 & 3.50\end{array}$

$\begin{array}{llll}22066094 & 20.46 & 37 & 1.83 \\ 22069011 & 43.16 & 16 & 1.67\end{array}$

$\begin{array}{llll}22090032 & 13.87 & 16 & 1.67 \\ 22091021 & 25.60 & 29 & 2.80\end{array}$

$\begin{array}{llll}22091021 & 25.60 & 29 & 3.00\end{array}$

$\begin{array}{llll}22091022 & 21.15 & 35 & 2.80\end{array}$

22091039

22091051

$\begin{array}{llll}99001111 & 17.54 & 46 & 1.00\end{array}$

$\begin{array}{llll}99007071 & 17.83 & 45 & 3.60\end{array}$

$\begin{array}{llll}99007108 & 60.98 & 9 & 1.00\end{array}$

$\begin{array}{llll}99007115 & 83.81 & 1 & 1.00\end{array}$

$\begin{array}{llll}99007116 & 15.70 & 49 & 1.17\end{array}$

$\begin{array}{llll}99008002 & 56.84 & 10 & 2.67 \\ 99008070 & 34.17 & 22 & 1.00\end{array}$

$\begin{array}{llll}99008070 & 34.17 & 22 & 1.00 \\ 99008080 & 23.92 & 31 & 1.50\end{array}$

99008080

99008098

99037017

99037039
99037044

99037046

99037049

99037051

99037053

99038002

99038005

99038007

99038012

99038013

99038022

99038026

99038036
99059016

99059019

99059043

99098008

99105008

9910508

$152 \times 11861$
2300103057

2305932018

9732-11

9732-19

$\begin{array}{llll}9732-24 & 36.73 & 20 & 1.60\end{array}$

$\begin{array}{llll}9732-31 & 16.85 & 47 & 1.17\end{array}$

9732-32

D105

D109

D110

D111

D113

D125

\begin{tabular}{llll} 
DN164 & 34.20 & 21 & 2.17 \\
\hline
\end{tabular}

$\begin{array}{lllll}59.42 & 36 & 8.77 & 29 & 1.40\end{array}$

$\begin{array}{lllll}23.13 & 49 & 7.49 & 43 & 2.00 \\ 38.93 & 46 & 8.85 & 25 & 1.75\end{array}$

$\begin{array}{lllll}120.18 & 1 & 9.27 & 10 & 2.00\end{array}$

$\begin{array}{lllll}55.07 & 41 & 8.06 & 34 & 1.17\end{array}$

$\begin{array}{lllll}86.33 & 23 & 8.32 & 32 & 1.50\end{array}$

$\begin{array}{lllll}87.29 & 22 & 9.13 & 17 & 1.50\end{array}$

$\begin{array}{lllll}103.05 & 9 & 8.94 & 23 & 1.83 \\ 75.40 & 27 & 7.93 & 36 & 2.33\end{array}$

$\begin{array}{lllll}100.98 & 11 & 9.26 & 11 & 1.33\end{array}$

$\begin{array}{lllll}103.65 & 8 & 9.13 & 18 & 1.33 \\ 106.55 & 5 & 9.93 & 3 & 1.17\end{array}$

$\begin{array}{lll}14.87 & 51 & 2.00 \\ 10.09 & 54 & 1.50\end{array}$

$58.35 \quad 37$

$\begin{array}{lllll}90.86 & 20 & 9.69 & 5 & 1.67\end{array}$

$\begin{array}{lllll}57.27 & 38 & 9.21 & 14 & 1.33 \\ 99.62 & 13 & 9.95 & 2 & 1.17\end{array}$

$\begin{array}{lll}19.38 & 42 \quad 2.33\end{array}$

$\begin{array}{lll}5.23 & 11 & 1.00 \\ 50.17 & 14 & 1.17\end{array}$

$\begin{array}{lllll}74.52 & 28 & 8.03 & 35 & 2.50\end{array}$

$\begin{array}{lllll}74.52 & 28 & 8.03 & 35 & 2.50 \\ 97.31 & 7 & 9.98 & 1 & 1.17 \\ 7.30 & 15 & 8.95 & 22 & 1.33\end{array}$

$\begin{array}{lllll}71.74 & 30 & 8.79 & 28 & 2.33\end{array}$

$\begin{array}{lll}7.96 & 55 & 2.00 \\ 74.57 & 4 & 1.00\end{array}$

$\begin{array}{lll}18.58 & 43 & 1.00\end{array}$

$\begin{array}{lllll}100.40 & 12 & 7.79 & 39 & 2.00\end{array}$

$\begin{array}{lllll}79.95 & 26 & 8.81 & 27 & 1.17\end{array}$

$\begin{array}{lllll}92.99 & 17 & 9.89 & 4 & 1.00\end{array}$

$\begin{array}{lllll}97.85 & 14 & 8.97 & 21 & 1.00\end{array}$

$\begin{array}{lllll}62.49 & 35 & 7.67 & 40 & 1.00\end{array}$

$\begin{array}{lllll}54.40 & 44 & 6.88 & 47 & 1.50\end{array}$

$\begin{array}{lllll}39.56 & 45 & 6.89 & 49 & 1.00\end{array}$

$69.57-31 \quad 9.51 \quad 9-2.20$

$\begin{array}{lll}5.14 & 50 & 1.50\end{array}$

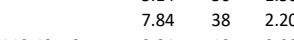

$\begin{array}{lllll}112.43 & 3 & 9.04 & 19 & 2.00\end{array}$

$\begin{array}{lllll}116.67 & 2 & 9.68 & 6 & 1.17\end{array}$

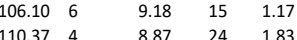

$\begin{array}{llllll}54.79 & 42 & 881 & 26 & 1.17\end{array}$

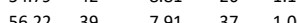

$\begin{array}{lll}56.22 & 39 & -7.91-37-1.00\end{array}$

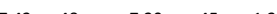

$\begin{array}{llllll}37.42 & 48 & 7.30 & 45 & 1.33\end{array}$

$\begin{array}{lllll}37.63 & 47 & 6.79 & 48 & 1.00\end{array}$

$\begin{array}{lllll}67.73 & 34 & 7.22 & 46 & 2.00\end{array}$

$\begin{array}{lllll}92.57 & 19 & 7.48 & 44 & 1.33\end{array}$

$\begin{array}{llll}\text { DN164 } & 34.20 & 21 & 2.17 \\ \text { DN2 } & 40.08 & 18 & 2.75\end{array}$

DN5

$\begin{array}{lllllllll}\text { NC14106 } & 38.68 & 19 & 1.20 & & & & \\ \text { NM6 } & 67.29 & 5 & 1.33 & 92.78 & 18 & 9.04 & 20 & 1.00\end{array}$

No canker scoring for Cornell. Canker scores have different bases for Escanaba and Tully (see Measurements section), and so cannot be directly compared.

The basis for clone rankings for MN is basal area (see Nelson et al., 2018), whereas in IN it was tree bole volume (see Nelson et al., 2019). Commercial check clones DN2, DN5 and NM6 are in bold. 
$\underline{\text { Table } 5}$

ANOVA and variance components for growth variables for the Escanaba, Cornell and Tully sites.

\begin{tabular}{|c|c|c|c|c|c|c|c|}
\hline Site & Variable & Unit & Parameters & $\begin{array}{l}\text { Degrees of } \\
\text { freedom }\end{array}$ & $\begin{array}{l}\text { Sum of } \\
\text { Squares }\end{array}$ & $\begin{array}{l}\text { Variance } \\
\text { components }\end{array}$ & $\begin{array}{l}\text { Variance } \\
\text { components, \% }\end{array}$ \\
\hline \multirow[t]{6}{*}{ Escanaba } & DBH & $\mathrm{cm}$ & Clone & 55 & 846 & 1.859 & $27.73 \%$ \\
\hline & & & Error & 262 & 1268 & 4.844 & $72.27 \%$ \\
\hline & $\mathrm{DBH}^{2}$ & $\mathrm{~cm}^{2}$ & Clone & 55 & 127415 & 276.8 & $27.15 \%$ \\
\hline & & & Error & 262 & 194651 & 742.8 & $72.85 \%$ \\
\hline & Height & $\mathrm{m}$ & Clone & 55 & 288.16 & 0.604 & $24.70 \%$ \\
\hline & & & Error & 262 & 480.56 & 1.841 & $75.30 \%$ \\
\hline \multirow[t]{4}{*}{ Cornell } & $\mathrm{DBH}^{2}$ & $\mathrm{~cm}^{2}$ & Clone & 48 & 164179 & 436.5 & $34.58 \%$ \\
\hline & & & Error & 243 & 200612 & 825.7 & $65.42 \%$ \\
\hline & Height & $\mathrm{m}$ & Clone & 49 & 149 & 0.3848 & $33.36 \%$ \\
\hline & & & Error & 248 & 191 & 0.7686 & $66.64 \%$ \\
\hline \multirow[t]{2}{*}{ Tully } & Height & $\mathrm{m}$ & Clone & 49 & 258 & 0.6368 & $27.60 \%$ \\
\hline & & & Error & 235 & 389 & 1.6702 & $72.40 \%$ \\
\hline
\end{tabular}

Results from the analysis of variance for growth on the Escanaba, Cornell and Tully sites are shown in Table 5. The growth parameters showed significant variations among clones, which explained around $25-35 \%$ of total variance at Escanaba, Cornell and Tully. This is comparable to $28 \%$ for the MN sites and $36 \%$ for the IN sites for growth. Variance components for all four regions indicate a strong clonal effect on growth rate. $\mathrm{DBH}, \mathrm{DBH}^{2}$, and height had similar variance components for the clone effect at the Escanaba and Cornell sites (Table 5), suggesting that the use of $\mathrm{DBH}$ or $\mathrm{DBH}^{2}$ at Tully would have given a similar clone effect with $\mathrm{DBH}$ or $\mathrm{DBH}^{2}$ as the measured variable.

The significant pseudo $R^{2}$ values (Table 6) for both the Escanaba and Tully sites indicate a significant clone effect on canker incidence. However, the pseudo $\mathrm{R}^{2}$ for Tully is only 0.24 , which suggests that most of the variation in canker incidence on that site is due to error. The pseudo $\mathrm{R}^{2}$ for Escanaba is 0.46 , indicating that variance in canker score is equally explained by clone and error on that site.

Table 6

The ordinal logistic model fit for canker score using clone as the predictor variable for the Escanaba and Tully sites.

\begin{tabular}{lllll}
\hline Site & Predictor Variable & Degree of Freedom & Prob>ChiSq & Pseudo R $^{2}$ \\
\hline Escanaba & Clone & 55 & $<0.0001$ & 0.4633 \\
Tully & Clone & 49 & $<0.0001$ & 0.2378 \\
\hline
\end{tabular}

Model fitting was performed in JMP Pro 14. Prob $<0.05$ indicates a significant fit. Pseudo $R^{2}$ was calculated by McFadden's $R$ squared measure.

\section{Clone ranks}

Clonal ranks for growth rate on the MN and IN sites are in Nelson et al. $(2018,2019)$. Clonal ranks for growth rate at Escanaba,
Cornell and Tully are shown in Table 4. Except for NM6 ranking within the top $10^{\text {th }}$ percentile at Escanaba, the three commercial check clones (NM6, DN2 and DN5) did not rank higher than the lower $68^{\text {th }}$ percentile on any site. Spearman's Test results for the between-site comparisons are shown in Table 7. For the 12 clones common to all sites, clone ranks were not correlated at the $p<0.05$ level for any site combinations. Clonal ranks in the 12 -clone test for MN versus IN and Escanaba versus Tully were close to significant ( $p>0.05$, but $<0.10$ ), although the Escanaba versus Tully rank coefficient was negative, indicating a reversal of rank order. In the 27-clone Spearman's Test for clones common to all sites except IN, only Cornell and Tully ranks were significantly correlated. Another Spearman's Test was done for rankings for $\mathrm{DBH}^{2}$ and height within the Escanaba and Cornell sites. The rankings for $\mathrm{DBH}^{2}$ and height were significantly correlated for both sites (Spearman's correlation coefficients $0.66-0.70$, significant at $p<0.001$ ), indicating that ranking based on height (Tully) is comparable to ranking based on $\mathrm{DBH}^{2}$ (Escanaba and Cornell). As reported in Nelson et al. (2019), for the 19 clones common to the MN and IN sites, the Spearman's Rank Coefficient was positive and significant at the $p<0.0001$, indicating no significant rank change in this comparison.

\section{Table 7}

Spearman's Tests of Rank Correlation for 12 clones common to all sites (MN, IN, Escanaba, Cornell and Tully) and for 27 clones common to all sites except IN. Growth parameters used for ranking were basal area for $\mathrm{MN}$, tree bole volume for $\mathrm{IN}_{1} \mathrm{DBH}^{2}$. for Escanaba and Cornell and tree height for Tully.

12 clones common to all sites:

\begin{tabular}{llllll}
\hline Variable & MN & IN & Escanaba & Cornell & Tully \\
\hline MN & & $\mathbf{0 . 5 2}$ & -0.02 & 0.24 & -0.01 \\
IN & 0.52 & & 0.17 & 0.41 & -0.04 \\
Escanaba & -0.02 & 0.17 & & -0.09 & -0.50 \\
Cornell & 0.24 & 0.41 & -0.09 & & 0.34 \\
Tully & -0.01 & -0.04 & -0.50 & 0.34 &
\end{tabular}

All $p$ are $>0.05$ for the 12 -clone test (non-significant). Coefficients in bold in the 12-clone test have $p>0.05$ and $<0.10$.

27 clones common to all sites except IN:

\begin{tabular}{lllll}
\hline Site & MN & Escanaba & Cornell & Tully \\
\hline MN & & -0.19 & 0.25 & 0.17 \\
Escanaba & -0.19 & & 0.19 & 0.030 \\
Cornell & 0.25 & 0.19 & & $0.57^{*}$ \\
Tully & 0.17 & 0.030 & $0.57^{*}$ &
\end{tabular}

Coefficients asterisked in the 27-clone test are significant at $p<0.05$.

Identifying broadly-adapted clones

Inter-regional and geo-robust clones are identified in Table 8, with 10 clones being geographically robust. All of the georobust clones are $\mathrm{D} \times \mathrm{N}$ hybrids with $\mathrm{MN} P$. deltoides female 
parents, and all were tested and screened in MN. Seven of the geo-robust clones are females, three are males.

Table 8

List of clones in top $10^{\text {th }}$ or $25^{\text {th }}$ percentile for growth rate on two or more sites. MN is mean rank of six sites. IN is mean rank of two sites. *are inter-regional clones. Clones in bold are geographically robust (geo-robust) clones.

\begin{tabular}{|c|c|c|c|c|c|c|c|c|c|c|c|}
\hline $\begin{array}{l}\text { Clone } \\
\text { (gender) }\end{array}$ & $\begin{array}{l}\text { MN } \\
\text { 10th }\end{array}$ & $\begin{array}{l}\text { MN } \\
25 \text { th }\end{array}$ & $\begin{array}{l}\text { IN } \\
10 \text { th }\end{array}$ & $\begin{array}{l}\text { IN } \\
25 \text { th }\end{array}$ & $\begin{array}{l}\text { Escanaba } \\
\text { 10th }\end{array}$ & $\begin{array}{l}\text { Escanaba } \\
\text { 25th }\end{array}$ & $\begin{array}{l}\text { Cornell } \\
\text { 10th }\end{array}$ & $\begin{array}{l}\text { Cornell } \\
25 \text { th }\end{array}$ & $\begin{array}{l}\text { Tully } \\
\text { 10th }\end{array}$ & $\begin{array}{l}\text { Tully } \\
\text { 25th }\end{array}$ & Cankered \\
\hline $99007071^{*}(\mathrm{~F})$ & & & $x$ & & & & $x$ & & & $x$ & yes \\
\hline $9732-19(\mathrm{~F})$ & & & & & & & $x$ & & & $x$ & no \\
\hline $9732-11 *(F)$ & & $x$ & & & & & $x$ & & & & no \\
\hline 99037017 (Unk) & & & & & & & $x$ & & $x$ & & no \\
\hline $9732-24^{*}(\mathrm{~F})$ & $x$ & & & & & & & $x$ & & & no \\
\hline $99038003^{*}(\mathrm{~F})$ & $x$ & & & & & $x$ & & $x$ & $x$ & & no \\
\hline $99008002^{*}(\mathrm{M})$ & & & & & & $x$ & & & $x$ & & no \\
\hline $502.37^{*}(\mathrm{M})$ & & & & & & $x$ & & $x$ & $x$ & & yes \\
\hline 99008081 (F) & & & & & & & & $x$ & & $x$ & no \\
\hline 99038013* (F) & & & & $x$ & & & & $x$ & & & no \\
\hline 99059016* (M) & $x$ & & & & $x$ & & & & & & no \\
\hline $\begin{array}{l}41700^{*}(F) \\
\text { (Aka 20173417) }\end{array}$ & & $x$ & & & $x$ & & & & & $x$ & no \\
\hline $152 \times 11861^{*}(\mathrm{M})$ & & & & & & $x$ & & & & $x$ & yes \\
\hline $99038005^{*}(\mathrm{~F})$ & $x$ & & & & & $x$ & & & & & no \\
\hline $99038022^{*}(\mathrm{~F})$ & $x$ & & $x$ & & & & & & & & no \\
\hline 99007116* (M) & & $x$ & & $x$ & & & & & & & no \\
\hline
\end{tabular}

Notes: Inter-regional clones are those within the top $10^{\text {th }}$ and/or $25^{\text {th }}$ percentile in growth rate in two or more regions out of the four regions. Regions are MN, IN, MI (Escanaba) and NY (Cornell, Tully). Cankered is a clone with moderate to heavy cankering on one or more sites in this study or in our experience in other field tests. Geographically robust clones are inter-regional clones without cankering. Gender: $F=$ female, $M=$ male, Unk = unknown = florals absent or not flowering at time of determination. Clone 41700 is numbered 20173417 in some previous reports. Clone values for $\mathrm{MN}$ and IN are from data in Nelson et al. $(2018,2019)$.

\section{Genetic gains for geo-robust and best clones for each site}

Genetic gains in growth relative to commercial check clones for geo-robust and best clones on each site are presented in Table 9. Specific clones used in the analysis for Table 9 are listed in Online Resource 1. Because all populations deployed in the trials were generally improved, and in order to eliminate the possibility that the genetic gains for the broadly adapted clones were not simply due to chance, we also compared genetic gains or reductions in growth for other (randomly chosen) clones not in the geo-robust and best clone populations (Table 9). In four out of five sites, the other (random) clones had a negative genetic gain, Cornell being the exception. For the sites for which genetic gain can be directly compared (MN, IN, Escanaba, Cornell), genetic gains for geo-robust clones exceeded that for the random clones by 24 to $44 \%$. Best clones and georobust clones were not significantly different in genetic gain and were significantly higher than other clones for the MN sites. For the IN sites, genetic gain for best clones was significantly higher (10-39\%) than for geo-robust clones, which in turn was higher than for other clones. Means for all sites showed a progression from best clones (highest genetic gain), georobust clones (intermediate genetic gain) to other clones (lowest genetic gain and negative for four out of five sites). However, except for MN and IN, geo-robust clones were not significantly different from other clones according to the SteelDwass test. But the trends in Table 9 are clear, so that the lack of rejecting the null hypothesis for the Escanaba, Cornell and Tully sites may be due to the small N (10) in each test not providing enough power to detect differences due to the large variance in the other clones category in all except the Escanaba site. The synthesis of all data indicates that the selection method for identifying geo-robust clones is valid.

Table 9

The mean, standard deviations and genetic gains for growth versus commercial check clones among three clone groups for five site groups. The mean values were compared among three clone groups by the non-parametric Steel-Dwass method in JMP Pro 14. Data designated with different letters are significantly different from other clone groups within same site.

\begin{tabular}{|c|c|c|c|c|c|c|c|}
\hline \multirow[t]{2}{*}{ Site (N) } & \multirow[t]{2}{*}{ Clone type } & \multicolumn{4}{|c|}{ Growth parameters } & \multicolumn{2}{|c|}{ Genetic gain, $\%$} \\
\hline & & Name & Unit & Mean & $\begin{array}{l}\text { Standard } \\
\text { deviation }\end{array}$ & Mean & $\begin{array}{l}\text { Standard } \\
\text { deviation }\end{array}$ \\
\hline MN & Best clones & Basal area & $\mathrm{cm}^{2}$ & $94.18^{A}$ & 5.63 & $49.4^{A}$ & 9.06 \\
\hline \multirow[t]{2}{*}{ (10) } & Geo-robust clones & Basal area & $\mathrm{cm}^{2}$ & $88.36^{A}$ & 13.05 & $40.1^{A}$ & 20.73 \\
\hline & Other clones & Basal area & $\mathrm{cm}^{2}$ & $60.73^{B}$ & 18.40 & $-3.7^{B}$ & 29.25 \\
\hline IN & Best clones & $\begin{array}{l}\text { Tree } \\
\text { volume }\end{array}$ & $\mathrm{cm}^{3}$ & $14620^{A}$ & 1602 & $66^{A}$ & 18.25 \\
\hline \multirow[t]{2}{*}{ (7) } & Geo-robust clones & $\begin{array}{l}\text { Tree } \\
\text { volume }\end{array}$ & $\mathrm{cm}^{3}$ & $11282^{B}$ & 1602 & $28^{B}$ & 18.02 \\
\hline & Other clones & $\begin{array}{l}\text { Tree } \\
\text { volume }\end{array}$ & $\mathrm{cm}^{3}$ & $8165^{c}$ & 1939 & $-7.29^{c}$ & 22.11 \\
\hline Escanaba & Best clones & $\mathrm{DBH}^{2}$ & $\mathrm{~cm}^{2}$ & $68.86^{A}$ & 8.81 & $28.3^{A}$ & 16.31 \\
\hline & Geo-robust clones & $\mathrm{DBH}^{2}$ & $\mathrm{~cm}^{2}$ & $47.86^{\mathrm{AB}}$ & 22.28 & $-10.7^{A B}$ & 41.66 \\
\hline & Other clones & $\mathrm{DBH}^{2}$ & $\mathrm{~cm}^{2}$ & $24.90^{B}$ & 12.51 & $-47.9^{B}$ & 24.04 \\
\hline Cornell & Best clones & $\mathrm{DBH}^{2}$ & $\mathrm{~cm}^{2}$ & $108.66^{A}$ & 6.09 & $45.7^{A}$ & 8.29 \\
\hline \multirow[t]{2}{*}{ (10) } & Geo-robust clones & $\mathrm{DBH}^{2}$ & $\mathrm{~cm}^{2}$ & $97.25^{8}$ & 10.67 & $29.7^{B}$ & 15.22 \\
\hline & Other clones & $\mathrm{DBH}^{2}$ & $\mathrm{~cm}^{2}$ & $78.49^{B}$ & 21.29 & $5.5^{B}$ & 28.57 \\
\hline Tully & Best clones & Height & $\mathrm{m}$ & $9.71^{A}$ & 0.23 & $16.5^{A}$ & 2.80 \\
\hline \multirow[t]{2}{*}{ (10) } & Geo-robust clones & Height & $\mathrm{m}$ & $8.91^{B}$ & 0.62 & $6.5^{\mathrm{B}}$ & 8.10 \\
\hline & Other clones & Height & m & $8.11^{B}$ & 1.21 & $-2.6^{B}$ & 14.38 \\
\hline
\end{tabular}

$\mathrm{N}$ is sample size for each clone group, equal to number of geo-robust clones on site. Check clone IDs: $\mathrm{MN}=$ DN2, NM6; IN = DN5, NM6; Escanaba = DN2, NM6; Cornell = DN5, NM6; Tully = DN5, NM6. Escanaba, Cornell and Tully are single sites. MN has 6 sites, described in Nelson et al. (2018). IN has 2 sites, described in Nelson et al. (2019).

Comparisons in table use geo-robust clones present on site and equal number of top-ranked clones (best clones) and equal number of other (random) clones that are not geo-robust or best clones for the site.

\section{Discussion}

According to genetic theory and empirical evidence, poplar hybrids are more likely to exhibit broad adaptability than pure natural species due to heterosis and increased heterozygosity (Lerner, 1954; Mitton and Grant, 1984; Gillespie and Turelli, 1989; Li and Wu, 1996; Wu, 1998; Zanewich et al., 2018). Recently, Zanewich et al. (2018) provided corroborating physiological evidence for this hypothesis by showing that heterosis in poplar hybrids is tied to phenotypic stability or environmental adaptability, with heterozygosity providing metabolic diversity that leads to better performance than parental pure species, particularly under suboptimal conditions. This body of 
literature foretells and underpins the identification of the broadly adapted genotypes reported here.

The variation in mean growth performance between sites reflects the high plasticity (low stability) of hybrid Populus genotypes (Nelson et al., 2018; Yu and Pulkkinen, 2003). This result is in line with the concept that riparian tree species such as $P$. deltoides and $P$. nigra may display high genetic variation and phenotypic plasticity to buffer against the spatial and temporal heterogeneity of the riparian habitat (Guet et al., 2015). As explained in Nelson et al. (2018), plasticity/stability of clonal populations do not necessarily equate to $\mathrm{G} \times \mathrm{E}$ interaction, as the latter is determined by both clone rank changes and relative performance of clones on different sites, also known as variance-changing interaction (Des Marais et al., 2013). If growth rates of individual clones change substantially between sites but the response slopes are relatively parallel, $\mathrm{G} \times \mathrm{E}$ will be minimized.

A useful approach in further studies of clones adapted to wide geographic ranges would be to monitor phenology (shoot initiation and growth cessation). Such studies could lead to a better understanding of the physiological mechanisms behind the geographic robustness of these clones and refinements in clonal selection (Nelson et al., 2019). Another approach to elucidating the mechanisms of clonal site specificity is to correlate clonal performance with physiography and growing conditions, such as the work of Ghezehei et al. (2019).

The clonal effect for growth was strong and similar across all four regions ( $\mathrm{MN}, \mathrm{IN}, \mathrm{MI}$ and NY) and was 2.5 to 4.1 times the clone $x$ site $(G \times E)$ interaction for the $M N$ and IN sites, respectively (Table 5) (Nelson et al., 2018; Nelson et al., 2019). The significant clonal effect on cankering at the Escanaba and Tully sites (Table 6) was expected from our experience with clone trials elsewhere over the last two decades.

The clonal populations tested here in all four regions were generally improved by the NRRI poplar program breeding process (Nelson et al., 2018), with only the Escanaba site having a commercial check clone (NM6) in the top $10^{\text {th }}$ or $25^{\text {th }}$ percentile for growth. Part of this improvement is undoubtedly the elimination of cold-susceptible clones and some diseased clones through prior screening in northern MN. For all sites except Escanaba, the commercial check clones ranked only within the lower $68^{\text {th }}$ percentile, and as low as the lowest $18^{\text {th }}$ percentile, for growth (Table 4) (Nelson et al., 2018; Nelson et al., 2019). Similarly, Zalesny et al. (2009) reported superior growth for another, earlier generation of experimental clones over that of commercial check clones in field tests encompassing sites in Minnesota, Wisconsin and lowa ranging from 45.7 to 42.0 degrees $\mathrm{N}$ latitude and 95.2 to 89.4 degrees $\mathrm{W}$ longitude.

There have been a few hybrid poplar clone tests with at least 40 clones per test across broad geographic regions, including Riemenschneider et al. (2001), Rae et al. (2008), Zalesny et al. (2009) and the Nelson et al. $(2018,2019)$ studies tied to this paper. Rae et al. (2008) primarily used $\mathrm{F}_{2}$ genotypes and thus is not comparable to the other cited studies, which used $\mathrm{F}_{1}$ clones.

The clonal composition of the Riemenschneider et al. (2001) and Zalesny et al. (2009) studies was very different from that of the present study. Those studies included disparate clone collections from a broad area of the Midwest USA. While D $x$ $\mathrm{N}$ hybrids selected and tested in $\mathrm{MN}$ predominated in our study, out of the 43 genotypes tested by Riemenschneider et al. (2001) and the 187 evaluated by Zalesny et al. (2009), only two were $\mathrm{D} \times \mathrm{N}$ hybrids. Pure $P$. deltoides clones (non-hybrids) predominated in both of those earlier studies, while the field trials in our study included no pure $P$. deltoides in the MN and Escanaba tests, whereas they represented $2 \%$ of the genotypes used in the IN study and $14 \%$ of those used at Cornell and Tully. These differences in clone populations compromise our ability to make comparisons with the earlier studies.

In contrast to the present study and Nelson et al. (2018, 2019), Riemenschneider et al. (2001) reported a clone x location effect of $20.6 \%$ for their earlier generation of clones, nearly double that of the clone effect for three sites, one each in MN (latitude 45.7 degrees N), WI (latitude 43.3 degrees N) and IA (latitude 42.0 degrees N). Likewise, Zalesny et al. (2009) stated that: "G $x \mathrm{E}$ interactions governed biomass production." In contrast to our study, Zalesny et al. (2009) included southern genotypes, which experienced winter dieback on the MN test site, and clones from the section Populus (the aspens), factors that are likely to have caused an increased G x E interaction. Clone mean rank correlations (Pearson's Correlation Coefficients) across sites in that study were all positive, ranged from 0.29 to 0.81 and were significant for 11 of 12 site comparisons. Significant $(p<0.01)$ Spearman's Coefficients of Rank Correlation between sites in our studies were: $\mathrm{MN}(6$ sites) $=+0.38$ to +0.72 ; IN ( 2 sites) $=+0.47$ to +0.57 ; and Cornell and Tully (clones common to all sites except IN; see Table 7) $=+0.57$. While these Pearson's and Spearman's coefficients cannot be directly compared, the range of values between our studies and Zalesny et al. (2009) are broadly similar. Obviously, the genetic composition of the clonal populations will affect variances and ranks. Zalesny et al. (2009) did identify individual clones that were stable across sites, consistent with the idea of safely deploying a limited number of genotypes broadly adapted to heterogeneous growing conditions within and across regions, as we hypothesize.

The significant Spearman's Rank Coefficient between the Cornell and Tully sites for the 27 clones common to all sites except IN (Table 7) is not surprising, given the close proximity of these field plots. As explained in Nelson et al. (2019), the similarity of ranks for the MN and IN sites was unexpected. The results in the present study show that both population rank similarities and individual clone performance must be considered in identifying geo-robust clones. For example, even though clonal ranks were similar for the MN and IN sites, only two clones (99038022 and 99007116) were in the top $25^{\text {th }}$ percentile for growth in both of these regions (Table 8).

Five of the 10 geo-robust clones (99038003, 99038013, 99038005; 9732-11 and 9732-24) are from only two full-sib D x $\mathrm{N}$ families $(038,032)$, indicating the family genome level and additive genetic variation (Berguson et al., 2017) are important in deriving geo-robust clones. However, it is unknown whether broad adaptability is strongly inherited, as heritability of growth stability, one component of adaptability, has been 
shown to be low for other crops (Becker and Leon, 1988). Two of the geo-robust clones (99059016 and 9732-24) were identified as stable clones (Finlay and Wilkinson, 1963) across the six MN sites (Nelson et al., 2018), further evidence that the methods we used here for identifying geo-robust clones have validity.

Although genetic gains are substantial with deployment of broadly adapted clones, there is a significant growth cost in genetic gain in deploying geo-robust clones instead of the best clones in each region or site (Table 9), an expected pattern from a genecology perspective (Farmer, 1996). As surmised from Zalesny et al. (2009) and the provenance literature for $P$. deltoides and other northern temperate tree species (Eldridge et al., 1972; Ying and Bagley, 1976; Loehle, 1998), the genetic gain for geo-robust clones was highest for the MN sites, as the $P$. deltoides clonal parents were almost all from MN provenances, and the hybrid clones were screened and tested in that state. If we assume that the best clonal performance on each site was at the low end of improvement possible using a sitespecific (narrow breeding zone) genetic improvement approach, we can conclude that the reductions in genetic gain over commercial check clones due to the use of geo-robust clones indicated in Table 9 are the minimums. The use of georobust clones on the Escanaba site actually produced a negative genetic gain, but all other sites exhibited large genetic gains for these clones, albeit less than the best clones for the sites. The genetic gain values for Tully cannot be compared directly with the other sites because tree height has a much lower coefficient of variation than do the other growth parameters. Excluding Tully, the geo-robust clones population averaged $21.8 \%$ genetic gain, while the equal number of best clones averaged $47.4 \%$. If we assume Escanaba is an outlier and exclude it as well as Tully, the comparison reveals a $32.6 \%$ genetic gain for geo-robust clones and $53.7 \%$ for the best clones. The average ranks over all sites for the populations are: geo-robust clones = top $31^{\text {th }}$ percentile, best clones $=$ top $11^{\text {th }}$ percentile.

Some reduction in genetic gain due to the use of broadly adapted clones was expected for our populations, as clone $\mathrm{x}$ site interaction was 9 to $11 \%$ of total variation for the MN and IN sites, even though this is only 25 to $39 \%$ of the amount of variation explained by clone (Table 5) (Nelson et al., 2018; Nelson et al., 2019). Under these genetic strictures, attempts to reduce $\mathrm{G} \times \mathrm{E}$ interaction will likely result in some reduction in genetic gain compared to using clones that are tailored to specific sites (Nelson et al., 2018).

From a practical investment perspective, the reduction in genetic gain for growth due to using broadly adapted clones has to be compared to the additional economic costs and benefits of multiple breeding zones. The costs of breeding specialist clones (Zalesny et al., 2009) and the concomitant necessity of narrow breeding zones are not trivial considerations when capital is limited.

There are two most important conclusions from this study. We have identified specific clones that can be deployed and may perform well over a wide geographic area delineated in this paper, with significant genetic improvement over current commercial clones. The results also suggest that one cost-effective approach may be a breeding and selection center in MN, with satellite testing of Populus from the MN program at strategic sites throughout much of the Midwest and Northeast USA.

\section{Acknowledgements}

At the University of Minnesota's NRRI in Duluth, development and testing of NRRI clones was funded by State of Minnesota appropriations to the Minnesota Hybrid Poplar Research Cooperative (MHPRC), State Special appropriations to the University of Minnesota Duluth Natural Resources Research Institute (NRRI), Minnesota Agricultural Utilization Research Institute (AURI) and U.S. DOE BETO Sun Grant Initiative Poplar Woody Crops Program (contract \# DEFC36-05GO85041). In addition, the following companies contributed through their membership in the MHPRC: Verso Corporation, Champion International, International Paper, Boise Cascade, Potlatch Corporation (now PotlatchDeltic), UPM-Blandin and Minnesota Power. Analysis and writing were funded by the USDA-NIFA Agriculture and Food Research Initiative Competitive Grants Program Sustainable Bioenergy and Bioproducts Challenge Area (grant no. 2018-68005-27635/project accession no. 1015244). Clones for the Minnesota, Michigan and New York sites were provided by the NRRI Poplar Program and the U.S. Forest Service Rhinelander Forestry Sciences Laboratory (Dr. Don Riemenschneider). Parents from outside the NRRI program used in producing inter-specific hybrids at NRRI were provided by the University of Minnesota (Dr. Carl Mohn's program), University of Toronto (the late Dr. Louis Zsuffa) and lowa State University (the late Dr. Rick Hall).

At Purdue University, this work (IN sites) is supported by McIntire-Stennis project accession no. 1016187 from the USDA National Institute of Food and Agriculture and was funded by a generous contribution from Hoosier Energy and a grant from the Mary S. Rice Farm Estate. Most of the clones in the IN tests were provided by GreenWood Resources (Rich Shuren) and by NRRI. We are also grateful to Matt Kraushar and the superintendents at the SWPAC and PPAC, Dennis Nowaskie and Jon Leuck, respectively, and their staff, particularly Angie Thompson and Bill Davis, for all of their hard work establishing, maintaining, measuring and harvesting the field trials.

At Michigan State University, this work (Escanaba site) was funded in part by the North Central Regional Sun Grant Center at South Dakota State University through a grant provided by the U.S. Department of Energy Biotechnologies Office under award number DE-FC3605G085041. Additional funding was provided by Michigan State University AgBioResearch. The technical assistance provided by Bradford Bender, Kile Zuidema and Paul Irving in planting, maintaining and measuring the clone trial is gratefully acknowledged. Planting material was supplied by NRRI.

At Cornell University, planting material was supplied by NRRI, and the authors gratefully acknowledge technical support from Michelle Serapiglia, Jane Petzoldt, Kayleigh Hogan 
and Cody Lafler, and partial financial support from the Cornell University College of Agriculture and Life Sciences.

At SUNY ESF, planting material for the Tully site was provided by NRRI. Assistance for establishing and maintaining the field trial was provided by Ken Burns, Karl Hallen, Justin Heavey and undergraduate student assistants.

Anda Bellamy is gratefully acknowledged for editing the paper for journal submission.

\section{References}

Becker HC and J Leon (1988) Stability analysis in plant breeding. Plant Breeding 101:1-23. https://doi.org/10.1111/j.1439-0523.1988.tb00261.x

Bentzer BG, GS Foster, HL Hellberg and AG Podzorski (1988) Geotype x environment interaction in Norway spruce involving three levels of genetic control: seed source, clone mixture, and clone. Canadian Journal of Forest Research 18(9):1172-1181. https://doi.org/10.1139/x88-180

Berguson WE, BG McMahon DE Riemenschneider DE (2017) Additive and non-additive genetic variances for tree growth in several hybrid poplar populations and implications regarding breeding strategy. Silvae Genetica 66:33-39. https://doi.org/10.1515/sg-2017-0005

Des Marais DL, KM Hernandez and TE Juenger (2013) Genotype-by-environment interaction and plasticity: exploring genomic responses of plants to the abiotic environment. Annual Review of Ecology, Evolution, and Systematics 44:5-29. https://doi.org/10.1146/annurev-ecolsys-110512-135806

Eldridge KG, AR Rout and JW Turnbull (1972) Provenance variation in the growth pattern of Populus deltoides. Australian Forest Research 5:45-50

Farmer RE Jr (1996) The genecology of Populus. In: Stettler RF, HD Bradshaw Jr, PE Heilman and TM Hinckley (eds) Biology of Populus and its implications for management and conservation. Canada: NRC Research, pp 33-55

Finlay KW and GN Wilkinson (1963) The analysis of adaptation in a plant-breeding programme. Australian Journal of Agricultural Research 14:742-754. https://doi.org/10.1071/AR9630742

Ghezehei SB, EG Nichols, CA Maier and DW Hazel (2019) Adaptability of Populus to physiography and growing conditions in the southeastern USA. Forests 10:118. https://doi.org/10.3390/f10020118

Gillespie JH and M Turelli (1989) Genotype-environment interactions and maintenance of polygenic variation. Genetics 121:129-138

Guet J, F Fabbrini, R Fichot, M Sabatti, C Bastien and F Brignolas (2015) Genetic variation for leaf morphology, leaf structure and leaf carbon isotope discrimination in European populations of black poplar (Populus nigra L.) Tree Physiology 35:850-863. https://doi.org/10.1093/treephys/tpv056

Lerner IM (1954) Genetic homeostasis. Edinburgh and London: Oliver \& Boyd Ltd, $134 \mathrm{p}$

Li B and R Wu (1996) Genetic causes of heterosis in juvenile aspen: a quantitative comparison across intra- and inter-specific hybrids. Theoretical and Applied Genetics 93:380-391. https://doi.org/10.1007/BF00223180

Loehle C (1998) Height growth rate tradeoffs determine northern and southern range limits for trees. Journal of Biogeography 25:735-742 https://doi.org/10.1046/j.1365-2699.1998.2540735.x

Mitton JB and Grant MC (1984) Associations among protein heterozygosity, growth rate, and developmental homeostasis. Annual Review of Ecology, Evolution, and Systematics 15:479-499. https://doi.org/10.1146/annurev.es.15.110184.002403

Nelson ND, WE Berguson, BG McMahon, M Cai and DJ Buchman (2018) Growth performance and stability of hybrid poplar clones in simultaneous tests on six sites. Biomass \& Bioenergy 118:115-125. https://doi.org/10.1016/j.biombioe.2018.08.007

Nelson ND, R Meilan, WE Berguson, BG McMahon, M Cai and D Buchman (2019) Growth performance of hybrid poplar clones on two agricultural sites with and without early irrigation and fertilization. Silvae Genetica 68:58-66. https://doi.org/10.2478/sg-2019-0011

Rae AM, MPC Pinel, C Bastien, M Sabatti, NR Street, J Tucker, C Dixon, N Marron, SY Dillen and G Taylor (2008) QTL for yield in bioenergy Populus: identifying
$\mathrm{G} \times \mathrm{E}$ interactions from growth at three contrasting sites. Tree Genetics \& Genomes 4:97-112. https://doi.org/10.1007/s11295-007-0091-3

Riemenschneider DE, WE Berguson, DI Dickmann, RB Hall, JG Isebrands, CA Mohn, GR Stanosz, GA Tuskan (2001) Poplar breeding and testing strategies in the north-central U.S.: Demonstration of potential yield and consideration of future research needs. The Forestry Chronicle 77(2):245-253. https://doi.org/10.5558/tfc77245-2

U.S. Department of Agriculture, Natural Resources Conservation Service (2019) Web Soil Survey. https://websoilsurvey.sc.egov.usda.gov/App/HomePage. htm

U.S. Department of Energy (US DOE) (2016) 2016 Billion-Ton Report: Advancing Domestic Resources for a Thriving Bioeconomy. In: Langholtz MH, BJ Stokes and LM Eaton (Leads) Volume 1: Economic Availability of Feedstocks. Oak Ridge, TN: ORNL/TM-2016/160, Oak Ridge National Laboratory. http://doi.org/10.2172/1271651

U.S. NOAA, National Centers for Environmental Information (2019) Available at https://www.usclimatedata.com/ U.S. Climate Data, three-decade (19812010) averages.

Wu R (1998) The detection of plasticity genes in heterogeneous environments. Evolution 52:967-977. https://doi.org/10.1111/j.1558-5646.1998.tb01826.x Ying CC and WT Bagley (1976) Genetic variation of eastern cottonwood in an eastern Nebraska provenance study. Silvae Genetica 25(2):67-73

Yu Q and P Pulkkinen (2003) Genotype-environment interaction and stability in growth of aspen hybrid clones. Forest Ecology and Management 173:25-35 https://doi.org/10.1016/S0378-1127(01)00819-2

Zalesny RS, RB Hall, JA Zalesny, BG McMahon, WE Berguson and GR Stanosz (2009) Biomass and genotype $x$ environment interactions of Populus energy crops in the Midwestern United States. BioEnergy Research 2:106-122. https://doi.org/10.1007/s12155-009-9039-9

Zanewich KP, DW Pearce and SB Rood (2018) Heterosis in poplar involves phenotypic stability: cottonwood hybrids outperform their parental species at suboptimal temperatures. Tree Physiology 38:789-800. https://doi.org/10.1093/treephys/tpy019 